Revista Eletrônica de Direito Processual - REDP.

Rio de Janeiro. Ano 11. Volume 18. Número 2. Maio a Agosto de 2017

Periódico Quadrimestral da Pós-Graduação Stricto Sensu em Direito Processual da UERJ

Patrono: José Carlos Barbosa Moreira. ISSN 1982-7636. pp. 245-260

www.redp.uerj.br

\title{
“JUSTIÇA RÁPIDA E BARATA PARA TODO O BRASIL", UM "CÓDIGO PARA \\ ACABAR COM AS CHICANAS DO DIREITO": O CÓDIGO DE PROCESSO \\ CIVIL DE 1939 E ALGUNS DISCURSOS SOBRE O JUDICIÁRIO ${ }^{1}$
}

\section{"A SWIFT AND AFFORDABLE JUSTICE FOR BRAZIL", A "CODE TO END THE DISTORTIONS OF LAW": THE CIVIL PROCEDURE CODE OF 1939 AND SOME SPEECHES ABOUT THE JUDICIARY}

Gustavo S. Siqueira

Professor de História do Direito na Faculdade de Direito da UERJ. Bolsista de Produtividade do CNPq e Pesquisador da FAPERJ. Coordenador do Laboratório Interdisciplinar de História do Direito (www.lihduerj.com). gustavosiqueira@uerj.br.

RESUMO: O presente trabalho se debruça sobre um dos períodos de maior produção normativa do Estado Novo. No período, a legislação brasileira ganha uma nova Constituição (1937) e novos Códigos. Busca-se, pela análise dos discursos da imprensa e doutrina do período, conhecer os contextos e as expectativas, as inovações nos debates jurídicos que existiam em 1939, durante a elaboração do Código de Processo Civil. Com isso, se pretende entender aquele universo de argumentos, propostas e preocupações e as esperanças e expectativas que eram geradas pelo novo Código.

PALAVRAS-CHAVE: Estado Novo - Código de Processo Civil - História do Direito.

ABSTRACT: This research focuses a period of great normative production of the "Estado Novo". At that time, Brazilian legislation conceived a Constitution (1937) an new Codes. Through the analysis of the discourses of the press and doctrine of the period, and its contexts, it seeks to understand the expectations, innovations and legal debates that existed

\footnotetext{
${ }^{1}$ Artigo recebido em 16/03/2017 e aprovado em 07/07/2017.
} 
Revista Eletrônica de Direito Processual - REDP.

Rio de Janeiro. Ano 11. Volume 18. Número 2. Maio a Agosto de 2017

Periódico Quadrimestral da Pós-Graduação Stricto Sensu em Direito Processual da UERJ

Patrono: José Carlos Barbosa Moreira. ISSN 1982-7636. pp. 245-260

www.redp.uerj.br

in 1939, during the preparation of the Civil Procedure Code. With this in mind, I want to know if that universe of arguments, proposals and concerns created by the new Code.

KEYWORDS: Estado Novo - Code of Civil Procedure - Legal History

\section{Introdução}

A ditadura do Estado Novo, iniciada em 11 de novembro de 1937, procedeu uma ampla reforma jurídica no Brasil. Foi elaborado um novo Código de Processo Civil em 1939, um novo Código de Processo Penal em 1941, uma Constituição em 1937, a primeira Consolidação das Leis Trabalhistas (CLT) do Brasil em 1943 e um Código Penal em 1940. As marcas do Estado Novo no sistema jurídico atual não são caracterizadas apenas pela vigência do Código Penal, da CLT e de várias leis. Acredito que o Estado Novo marca a cultura jurídica nacional como um todo e estudar os institutos existentes naquele período mesmo aqueles revogados - é entender um pouco da formação da cultura jurídica nacional.

O presente artigo pretende estudar os discursos na imprensa e na doutrina do período sobre a construção do Código de Processo Civil de 1939. Vigente até a promulgação do Código de 1973, talvez as antigas marcas do Código de 1939 agora possam ser revistas no Código de Processo Civil, aprovado em 2015.

Desta forma, procuro entender os contextos, as expectativas, as inovações e os debates jurídicos que existiam em 1939 para, a partir de tal conjuntura, contribuir para o debate jurídico atual, não como um passado atual, mas como um espaço de experiências hábeis a colaborar para os debates do futuro. Não abordarei aqui todas as inovações ou conceituações trazidas pelo Código de 1939, mas focarei nas principais discussões da imprensa e das fontes da época. 


\section{Investigando os argumentos}

Justiça rápida e barata para todo o Brasil" essa era a notícia principal do Jornal "A Noite", em 12 de dezembro de 1937, domingo. A reportagem anunciava o acompanhamento dado a Comissão designada pelo Ministro da Justiça - Francisco Campos - para a elaboração do novo Código de Processo Civil e Comercial. Na capa, o jornal anunciava detalhes das "inovações" das Codificações que se estavam discutindo - também um novo Código de Processo Penal - e apresentava uma entrevista com Pedro Baptista Martins, membro da Comissão e principal redator do Código de Processo Civil de 1939.

Reconstruir o passado jurídico exige uma busca multidisciplinar de fontes, especialmente em uma ditadura, com censura, restrições à publicações e discursos laudatórios, a reconstrução e construção do leque de fontes deve ser cuidadoso.

Para analisar o que se esperar do novo Código analisei dois tipos de fontes: os jornais e a Revista Forense. A partir de uma imagem daquilo que se publicava para a sociedade em geral e daquilo que se publicava para um corpo especializado, investiguei autores de direito processual da época e dicionários do período, muitos deles sem data de publicação, mas que inclui no período por conta de informações internas, como prefácios e apresentações.

Desta forma, na primeira parte do artigo, analiso as esperanças do novo Código na imprensa da época para, na segunda, analisar o Código em si - o que se incluiu ou não - e a doutrina da época. Decidi incluir a exposição de motivos e o debate sobre o Código na Faculdade de Direito da Universidade de São Paulo na primeira parte, pois ambos foram publicados pela imprensa e divulgados com o novo texto legal.

Restringida pelo tempo e pelo espaço, o quadro de fontes é pequeno, especialmente em relação ao número de periódicos, mas pode auxiliar, de alguma forma, a vinda da nova Codificação. 
Revista Eletrônica de Direito Processual - REDP.

Rio de Janeiro. Ano 11. Volume 18. Número 2. Maio a Agosto de 2017

Periódico Quadrimestral da Pós-Graduação Stricto Sensu em Direito Processual da UERJ

Patrono: José Carlos Barbosa Moreira. ISSN 1982-7636. pp. 245-260

www.redp.uerj.br

\section{Esperanças, desejos e projetos}

Durante os anos de 1937, 1938, 1939 e 1940 foi comum observar notícias da imprensa nacional sobre os novos Códigos. Desejos, esperanças, crenças em um Poder Judiciário mais célere, justo e eficiente eram depositadas nas novas leis. ${ }^{2}$

Os jornais também anunciavam constantemente as prováveis alterações dos novos diplomas legais e divulgavam as revistas jurídicas do período, como a Revista Forense, que constantemente faziam edições especiais sobre os novos temas jurídicos. A discussão das novas criações jurídicas, aparentemente, permeava o debate nacional.

Obviamente que, em tempos de ditadura, qualquer olhar sobre a imprensa deve ser cauteloso. Mas, mesmo com as ressalvas, as publicações da imprensa podem ajudar a compreender uma parte do que se pensava em relação ao novo Código, bem como as ideias e propagandas sobre ele veiculadas.

As notícias sobre o novo Código de Processo Civil eram constantes nos jornais publicados no final do ano de 1937. A comissão coordenada por Pedro Baptista Martins era, de certa forma, a esperança de uma mudança radical no judiciário brasileiro.

Em 05 de dezembro de 1937, o jornal carioca "A Noite" publicava notícias sobre a comissão. Na página 3 do jornal, a manchete "Justiça rápida" informava aos leitores que o periódico tinha conseguido apurar que o novo anteprojeto restringia o "número de recursos das sentenças e despachos proferidos pelos juízes". Tinha-se a esperança que com o novo Código não se permitiria a repetição do "que até agora vem se verificando em novos foros, em que uma ação, antes de chegar ao seu termo sofre inúmeros recursos (...) a maioria tendo em vista a protelação da sentença final”. Uma das inovações descritas pelo jornal era a transformação do agravo, que só seria permitido em casos especiais.

No dia 12 de dezembro de 1937, a capa do jornal estampava a manchete: "Justiça rápida e barata para todo o Brasil". Em entrevista ao jornal, o coordenador do anteprojeto do Novo Código Civil, Pedro Baptista Martins, que apresentava à imprensa algumas das inovações do futuro Código: a ideia do novo diploma legal era a simplificação do processo,

\footnotetext{
${ }^{2}$ Vide "A Noite", de 02 de fevereiro de 1938.
} 
Revista Eletrônica de Direito Processual - REDP.

Rio de Janeiro. Ano 11. Volume 18. Número 2. Maio a Agosto de 2017

Periódico Quadrimestral da Pós-Graduação Stricto Sensu em Direito Processual da UERJ

Patrono: José Carlos Barbosa Moreira. ISSN 1982-7636. pp. 245-260

www.redp.uerj.br

com uma economia de tempo e direito para as partes e para o Judiciário. $\mathrm{O}$ advogado também criticava o sistema processual vigente pela lentidão e pelo descompromisso com a Justiça. Informava também que o processo teria duas fases iniciais escritas - petição inicial e contestação - e depois seria, eminentemente, oral, "facilitando grandemente ao juiz a inteligência dos fundamentos em que se baseia a ação".

Pedro Baptista Martins também criticava o agravo, descrevendo-o como um recurso de "chicana", que era constantemente usado como abuso dos processos. A partir do novo Código, segundo Martins, o agravo teria caráter de reclamação, não importando a suspensão do processo.

O coordenador da comissão também prometia a entrega do anteprojeto até o final do mês de dezembro para o Ministro Francisco Campos. Com a ditadura e o fechamento do Congresso, o futuro código não seria debatido pelo poder legislativo, mas apenas promulgado, após as decisões do poder executivo.

O mesmo jornal anunciava, em 15 de dezembro de 1937, a criação de multas e penalidades impostas aos funcionários da Justiça e Advogados que perturbassem, com atos de "Chicana", o andamento do processo. Outra informação publicada no mesmo dia informava a criação da figura do "Juiz-delegado", que existiria para coligir as provas do processo e proceder nos casos em que fossem envolvidos os funcionários da Justiça culpados de protelação dos processos.

Nos dicionários da época o termo "chicana" era comum e se relacionava às questões jurídicas. Para Cândido de Figueiredo, era uma tramoia em questões judiciais, um ardil, uma contestação capciosa. Para o autor a palavra vinha do francês, Chicane. ${ }^{3}$ Para Hildebrando Lima e Gustavo Barroso ${ }^{4}$, um enredo em questões judiciais. Para Simões da Fonseca, um sofisma de advogado para iludir a lei; como exemplo, citava: usar de chicana em matéria de processo, contestar sem fundamento, suscitar dificuldades por capricho e má fé. ${ }^{5}$

\footnotetext{
${ }^{3}$ FIGUEIREDO, Cândido de. Novo Diccionário da Lingua Portuguesa. Lisboa: Portugal - Brasil. Sociedade Editora Arthur Brandão \& Cia. Rua da Condessa, 80, p. 442.

${ }^{4}$ LIMA, Hildebrando; BARROSO, Gustavo. (org.) Pequeno Dicionário Brasileiro da Língua Portuguesa. Editora Civilização Brasileira S|A: RJ, SP e BA. 8ed, 1949. p. 280.

${ }^{5}$ FONSECA, Simões da. Diccionario Encyclopedico. Rio de Janeiro: rua Moreira-cezar,71 | Pariz: rue des Saints-Pères,6. H. Garnier, Livreiros - Editores. p. 328.
} 
Revista Eletrônica de Direito Processual - REDP.

Rio de Janeiro. Ano 11. Volume 18. Número 2. Maio a Agosto de 2017

Periódico Quadrimestral da Pós-Graduação Stricto Sensu em Direito Processual da UERJ

Patrono: José Carlos Barbosa Moreira. ISSN 1982-7636. pp. 245-260

www.redp.uerj.br

Observou-se, portanto, que o novo Código seria um instrumento para acabar com os atrasos, com as malicias processuais, com os entraves para os julgamentos.

Por outro lado, as notícias nos jornais também eram confusas e, às vezes, contraditórias. Talvez esse fosse o ritmo de um projeto de estava se desenhando. Algumas alterações viriam, outras não.

No dia 20 de dezembro de 1937, por exemplo, o jornal "A Noite" anunciava a redução das férias dos juízes para 15 dias, "em igualdade de condições com outros funcionários públicos", e a suspensão do funcionamento do foro por 90 dias, o que acontecia entre janeiro e março todos os anos. Já no dia 23 de dezembro, o mesmo jornal anunciava a alteração das férias dos magistrados de 45 para 60 dias.

Os jornais nacionais publicaram dezenas de notícias sobre o anteprojeto do novo Código de Processo Civil no ano de 1938. O debate sobre as férias estampou os jornais em fevereiro de $1938 .^{6}$

No dia 09 de março de 1938, na capa, “A Noite" anunciava: "Pronto o novo Código de Processo Civil e Comercial". O anteprojeto seria enviado pelo autor, Pedro Baptista Pereira, para o Ministro de Justiça.

Em primeiro de abril de 1938, anunciava, na página 3, que o anteprojeto do novo Código já estava nas mãos no Ministro da Justiça Francisco Campos, que "vem procedendo, ele próprio a revisão do trabalho daquele causídico" e que findo o trabalho, o levará ao Presidente da República para ser convertido em lei.

O jornal também publicava diversas notícias esparsas sobre o novo projeto; recorrentemente, novos temas apareciam, como a criação da justiça gratuita, divulgada em 04 de abril de 1938. Em outros momentos, temas já noticiados eram novamente veiculados, como o fim das férias forenses, propagado em 31 de março de 1938, bem como em outras edições.

Francisco Morato, professor de direito judiciário civil e diretor da Faculdade de Direito da Universidade de São Paulo, em maio de 1938, publicou, na revista forense, um

\footnotetext{
6 "A noite", 01 de fevereiro de 1938, p. 3.
} 
Revista Eletrônica de Direito Processual - REDP.

Rio de Janeiro. Ano 11. Volume 18. Número 2. Maio a Agosto de 2017

Periódico Quadrimestral da Pós-Graduação Stricto Sensu em Direito Processual da UERJ

Patrono: José Carlos Barbosa Moreira. ISSN 1982-7636. pp. 245-260

www.redp.uerj.br

artigo chamado "A oralidade", destacando a importância da oralidade no processo, como uma das inovações do novo Código para a atuação do juiz no processo.

Em 10 de julho de 1938 foi noticiado pelo “A Noite" o envio do anteprojeto, revisado pelo Ministro da Justiça, para o presidente Getúlio Vargas.

Em outubro de 1938 a Revista Forense publicou entrevista com Pedro Baptista Martins, que explicava as orientações políticas e as inovações da nova lei processual. A oralidade era um dos destaques. ${ }^{8}$

Após revisão dos juízes Nelson Hungria e Guilherme Estelita, segundo informações do jornal "A noite", de 01 de fevereiro de 1939, o anteprojeto foi publicado em 04 de fevereiro de 1939.

Os jornais anunciavam, antes e depois da publicação, a reunião de grupos, como dos promotores públicos, ${ }^{9}$ Tribunal de Alçada de São Paulo, Instituto dos Advogados de São Paulo, Club dos Advogados do Rio de Janeiro, Professores Universitários, para o envio de sugestões para o novo Código. ${ }^{10}$ As sugestões deveriam ser enviadas diretamente para o Gabinete do Ministro Francisco Campos.

Em 17 de maio de 1939, Pedro Baptista Martins, autor do anteprojeto, após o convite do Instituto dos Advogados de São Paulo, fez uma conferência na Faculdade de Direito da Universidade de São Paulo intitulada "Em defesa do Anteprojeto de Código de Processo Civil. $^{11}$

Nessa oportunidade, Martins informa as sugestões que o anteprojeto, publicado pelo Governo Federal, recebeu de professores de direito, afirmando que, apesar do direito romano ter marcado a "mentalidade dos nossos magistrados e dos nossos juristas", já não é o direito romano "a fonte onde o legislador ou o magistrado moderno deve alimentar suas convicções”. O legislador que procurar, segundo Martins, na restauração das noções

\footnotetext{
${ }^{7}$ MORATO, Francisco. A oralidade in Revista Forense, Rio de Janeiro, Ano XXXV, número 419, p. 11-16.

${ }^{8}$ MARTINS, Pedro Baptista. O Código de Processo Civil e Comercial do Brasil in Revista Forense, Rio de Janeiro, Ano XXXV, número 424, p. 166-167.

9 "A noite", 04 de abril de 1939, p. 1.

10 "A noite", 05 de abril de 1939, "A noite”, 07 de fevereiro de 1939.

${ }^{11}$ CAMPOS, Francisco. Exposição de Motivos. In MARTINS, Pedro Baptista e LEAL, Victor Nunes. Código de Processo Civil. Rio de Janeiro: José Olympio Editora, 1939, p. XXVIII.
} 
Revista Eletrônica de Direito Processual - REDP.

Rio de Janeiro. Ano 11. Volume 18. Número 2. Maio a Agosto de 2017

Periódico Quadrimestral da Pós-Graduação Stricto Sensu em Direito Processual da UERJ

Patrono: José Carlos Barbosa Moreira. ISSN 1982-7636. pp. 245-260

www.redp.uerj.br

romanas a solução dos problemas, "terá estabelecido um divórcio irremediável entre justiça e realidade". ${ }^{2}$

Citando Chiovenda, Calamandrei, Geny e Kelsen, o texto de Martins é técnico e defendia as alterações que estavam sendo discutidas. Na fala dele a modernização é jurídica, com novos institutos e novas formas de se aplicar o direito.

Consciente de que a concepção do Estado assume formas novas, as indústrias se desenvolvem, as classes sociais lutam pelo equilíbrio político e a humanidade procura um "refúgio na solidariedade, que se tornou a leis dos povos evoluídos", Martins apresenta, entre os deveres institucionais do Estado, a prestação jurisdicional. ${ }^{13}$

Para o advogado, a jurisdição não é uma prerrogativa do juiz ou uma simples atividade lógica, mas um poder público, derivado da soberania. Desta forma, só através da ação que pode aplicar o Estado qualquer tipo de sanção ao particular. O processo, de certa forma, é o fundamento da legalidade. ${ }^{14}$

Por outro lado, "numa época em que os meios de comunicação não só se multiplicam, mas, aperfeiçoaram-se de tal modo que as distâncias intercontinentais se eliminaram" só a técnica processual "continua a mesma de que se serviram os nossos mais remotos antepassados"15. Assim, foi necessária a renovação do processo para evitar a "submissão do processo à tirania do formalismo" e das nulidades. ${ }^{16}$

A simplificação do processo, as necessidades do homem contemporâneo, as alterações no consumo clamavam por alterações no direito processual. Neste sentido, uma sentença que demorava cinco anos, depois do titular ter seu direito violado, corria o risco de ser apenas uma satisfação puramente moral. ${ }^{17}$

Uma das formas pensadas por Martins para a celeridade processual seria a oralidade. O processo oral "resolve-se em poucos princípios interdependentes, cuja adoção importa na

\footnotetext{
12 Ibidem.

${ }^{13}$ Ibidem.

${ }^{14}$ Ibidem, p. XXIX.

15 Ibidem, p. XXIX.

${ }^{16}$ Ibidem.

${ }^{17}$ Ibidem, p. XXX.
} 
Revista Eletrônica de Direito Processual - REDP.

Rio de Janeiro. Ano 11. Volume 18. Número 2. Maio a Agosto de 2017

Periódico Quadrimestral da Pós-Graduação Stricto Sensu em Direito Processual da UERJ

Patrono: José Carlos Barbosa Moreira. ISSN 1982-7636. pp. 245-260

www.redp.uerj.br

impossibilidade da eternização do litigo". ${ }^{18}$ Outra medida adotada foi a restrição dos recursos cabíveis das decisões interlocutórias, fazendo que aquele, quando aconteça, não suspenda o processo.

Procedimentos especiais nas ações de alimentos, nas leis trabalhistas e a impenhorabilidade do prédio ${ }^{19}$ rural eram vistos por Martins como a humanização do processo: "com a consagração dessas medidas, a nova ordem processual, cujo advento se aguarda, terá contribuído poderosamente para a humanização do direito, empreendida pelo governo do eminente Senhor Getúlio Vargas, em todos os setores da atividade jurídica nacional". ${ }^{20}$

Encerrando seu discurso, Martins afirmou: “tenho fé apostólica nos resultados práticos da execução do novo sistema processual, porque confio na prudência e na dedicação da magistratura brasileira, na sinceridade e cultura dos advogados e na indestronável superioridade do procedimento oral. ${ }^{21}$

Em 24 de julho de 1939, o Ministro Francisco Campos entregou ao Presidente Getúlio Vargas o novo Código de Processo Civil com a exposição de motivos.

Nesta, Campos afirma que a "nova ordem jurídica reclamava um instrumento mais popular e eficiente para a distribuição da justiça". ${ }^{22}$ Da mesma forma, a "própria ciência do processo" exigia que se "atualizasse o confuso e obsoleto corpo de normas" que regia a aplicação da lei no país. Para Campos as leis processuais no Brasil estavam atrasadas, o processo era mais "uma congérie de regras, de formalidades e de minúcias rituais e técnicas a que não se imprimira nenhum espírito de sistema" e de, de certa forma, não contribuía para tornar eficaz o direito. ${ }^{23}$

No tópico, "o processo como instrumento de dominação política", Campos afirmou que "o processo em vigor, formalista e bizantino, era apenas um instrumento das classes

\footnotetext{
${ }^{18}$ Ibidem, p. XXXI.

${ }^{19}$ De valor inferior a três contos de réis, desde que o devedor tenha nele a sua moradia e o cultive com o trabalho próprio ou da família.

${ }^{20}$ Ibidem, pp. XXXVI-XXXVII.

${ }^{21}$ Ibidem, p. XLI.

${ }^{22}$ CAMPOS, Francisco. Exposição de Motivos. In MARTINS, Pedro Baptista e LEAL, Victor Nunes. Código de Processo Civil. Rio de Janeiro: José Olympio Editora, 1939, p. VII.

${ }^{23}$ Ibidem.
} 
Revista Eletrônica de Direito Processual - REDP.

Rio de Janeiro. Ano 11. Volume 18. Número 2. Maio a Agosto de 2017

Periódico Quadrimestral da Pós-Graduação Stricto Sensu em Direito Processual da UERJ

Patrono: José Carlos Barbosa Moreira. ISSN 1982-7636. pp. 245-260

www.redp.uerj.br

privilegiadas, que tinham lazer e recursos suficientes para acompanhar os jogos e as cerimônias da justiça, complicados nas suas regras, artificiosos na sua composição e, sobretudo, demorados no seu desenlace". Com as transformações políticas do novo governo, era necessária uma nova administração da justiça e a transformação da justiça à categoria de um bem geral. ${ }^{24}$

Interessante perceber como o discurso de Campos é carregado de uma ideia de modernização do Estado, feita pela ditadura do Estado Novo, e que, dentro deste processo, carrega também o direito. Para o Ministro, a concepção dualística do processo deveria ser substituída por uma "concepção autoritária do processo". ${ }^{25}$ Nela "a concepção do processo como instrumento de luta entre particulares, haveria de substituir-se a concepção do processo como instrumento de investigação da verdade e distribuição da justiça." ${ }^{26}$ Sob o argumento de um maior "sentido popular do novo sistema" - e aqui Campos parece não se limitar ao processo, mas dialogar com toda a legislação do governo Vargas - era construído um modelo autoritário. $^{27}$

Apesar de dizer que acredita que a autoridade dos juízes não está ligada ao caráter autoritário dos Estados, citando o exemplo de democracias, como os Estados Unidos e a Inglaterra, Campos, de certa forma, não deixa de relacionar intimamente o juiz com o Estado Novo.

Campos defende que o regime instituído em 10 de novembro de 1937 constituiu-se na restauração da autoridade e do caráter popular do Estado. ${ }^{28}$ Nesse sentido é que ele acredita que somente a intervenção ativa do Estado no processo pode remover as causas de injustiça." 29 Ditadura e populismo andam juntos nos discursos de Ministro da Justiça. É como se o Estado Novo - por seu ditador ou por seus juízes - fosse habilitado; para ouvir os sentimentos populares e decidire.

\footnotetext{
${ }^{24}$ Ibidem, p. VIII.

${ }^{25}$ Ibidem.

${ }^{26}$ Ibidem.

${ }^{27}$ Ibidem.

${ }^{28}$ Ibidem, p. XI.

${ }^{29}$ Ibidem, p. IX.
} 
Revista Eletrônica de Direito Processual - REDP.

Rio de Janeiro. Ano 11. Volume 18. Número 2. Maio a Agosto de 2017

Periódico Quadrimestral da Pós-Graduação Stricto Sensu em Direito Processual da UERJ

Patrono: José Carlos Barbosa Moreira. ISSN 1982-7636. pp. 245-260

www.redp.uerj.br

Na reforma, não compete apenas ao juiz o papel de "zelar pela observância formal das regras processuais", mas ele deve intervir no processo de maneira que este atinja os meios adequados, a investigação dos fatos e a descoberta da verdade: “o juiz ordenará o que for necessário ao conhecimento da verdade" ${ }^{30}$, “o juiz é o Estado administrando a justiça"31.

Por outro lado, apesar de parecer contraditório ao que foi ponderado anteriormente, para Campos, mesmo em um Estado autoritário, pelo menos em teoria, "não fica um juiz autorizado a julgar com inobservância das regras estabelecidas pela lei”32.

Após uma apresentação da teoria dos motivos do novo Código, Campos passa às inovações técnicas do projeto: a abolição dos despachos interlocutórios, a reforma das nulidades, "que sempre foram instrumento de chicana, das dilações e dos retrocessos processuais", a oralidade e a identidade do juiz.

Destaque especial tem a oralidade no processo, em que o juiz que julga a causa deve ter contato com a testemunhas e as partes. Campos enfrenta as críticas e as dúvidas que o sistema oral apresenta e cita uma série de juristas que clamavam por uma alteração orientada pelos princípios da oralidade no sistema processual.

O autor encerra a exposição de motivos citando o trabalho de Pedro Baptista Martins e as diversas sugestões que o Ministério da Justiça recebeu após a publicação do anteprojeto.

A Constituição de 1937, nas palavras de Campos, possibilitou o fortalecimento do poder central e, consequentemente, possibilitou a unidade política do país e a unidade processual que seria consagrada, agora, pelo novo Código de Processo Civil.

Em outubro de 1939 a Revista Forense publicou a exposição de motivos e fez um volume especial sobre o novo Código. Na edição de dezembro do mesmo ano, o texto do novo Código foi publicado na Revista.

\footnotetext{
${ }^{30}$ Ibidem, p. XI.

${ }^{31}$ Ibidem, p. XII.

${ }^{32}$ Ibidem, p. XVI.
} 
Revista Eletrônica de Direito Processual - REDP.

Rio de Janeiro. Ano 11. Volume 18. Número 2. Maio a Agosto de 2017

Periódico Quadrimestral da Pós-Graduação Stricto Sensu em Direito Processual da UERJ

Patrono: José Carlos Barbosa Moreira. ISSN 1982-7636. pp. 245-260

www.redp.uerj.br

\section{O Código de Processo Civil e Comercial de 1939}

Por vezes chamado apenas de Código de Processo Civil, o mesmo também tinha no nome o Direito Comercial. Com o Congresso Nacional fechado, o Decreto-Lei n. 1.608, publicado em 18 de setembro de 1939, assinado pelo Presidente Getúlio Vargas e pelo Ministro da Justiça Francisco Campos, outorgava o Código de Processo Civil e Comercial, que seria vigente a partir de 01 de fevereiro de 1940. Possuindo 1052 artigos, o Código tornou-se a maior construção jurídica do Governo Vargas. Com o início da vigência, o Código seria aplicado a todos os processos no país, pendentes ou não.

A doutrina recebeu com elogios o novo Código, mas, talvez, a ditadura pudesse influir nos juristas. ${ }^{33}$

A.L. Câmara Legal, que dedicava seu livro ao "eminente brasileiro" Getúlio Dorneles Vargas, "unificador do processo civil brasileiro, o reformador de nossas instituições, o impulsionador do direito social, o criador do Estado Novo, do qual vem ressurgindo um Brasil coeso, gigante e forte", teceu vários elogios ao texto. Dizendo-se orientado pelo "espirito da imparcialidade" e lembrando que ao "jurista deve ser facultada a liberdade de crítica", apresentava seu livro em abril de $1940 .{ }^{34}$

Francisco Raitani apresentava o livro com a intenção de tirar o Processo Civil do anacronismo, questionando o sacrifício do mérito pelo acordo. Defendia um novo método na "arte de advogar", expondo o fato, examinando-o à luz do direito, em matéria de prova e julgando ao final. O livro de Raitani aborda praticamente todos os temas do novo Código. ${ }^{35}$

Também foi comum perceber nos $\operatorname{livros}^{36}$ e revistas consultas à publicação da exposição de motivos do Ministro Francisco Campos.

\footnotetext{
${ }^{33}$ Sobre juristas e ditadura: SIQUEIRA, Gustavo et ali. The constitutionalists in the Brazilian Estado Novo: notes on the right to strike In Revista da Academia brasileira de Direito Constitucional, v. 8, 2016, Curitiba, pp. 12-32 e SEELAENDER, Airton. Juristas e ditaduras: uma leitura brasileira In FONSECA, Ricardo Marcelo e SEELAENDER, Airton (Org.). História do Direito em Perspectivas. Curitiba: Juruá, 2009.

${ }^{34}$ CÂMARA LEGAL. A.L.. Comentários ao Código de Processo Civil. Rio de Janeiro: Forense, 1942.

${ }^{35}$ RAITANI, Francisco. Prática de Processo Civil, $3^{\text {a }}$ ed., Editora Guaíra Limitada: Curitiba.

${ }^{36}$ Um outro exemplo: DE PLÁCIDO E SILVA. Técnica Forense e Prática Processual. Editora Guaíra Limitada: Curitiba.
} 
Revista Eletrônica de Direito Processual - REDP.

Rio de Janeiro. Ano 11. Volume 18. Número 2. Maio a Agosto de 2017

Periódico Quadrimestral da Pós-Graduação Stricto Sensu em Direito Processual da UERJ

Patrono: José Carlos Barbosa Moreira. ISSN 1982-7636. pp. 245-260

www.redp.uerj.br

$\mathrm{O}$ artigo $2^{\circ}$ do Código regulamentava a necessidade de legítimo interesse econômico ou moral para propor ou contestar uma ação.

O artigo 39 acabava com as férias forenses nas Capitais e determinava as férias de 60 e 30 dias para autoridades judiciárias e serventuários da Justiça, respetivamente. O Juiz de primeira instância não poderia entrar em gozo de férias enquanto não julgar a causa cuja instrução tenha presidido. ${ }^{37}$

A justiça gratuita, por força do artigo 68, era um benefício concedido a parte que não tivesse condições de pagar as custas do processo sem prejuízo do sustento próprio ou da família. O benefício era amplo, estendia-se a todas as instâncias e a todos os custos de um processo. Por meio do artigo 68 e seguintes, um processo poderia ser totalmente gratuito inclusive com a nomeação de advogado pelo juiz - para as partes hipossuficientes.

A mulher casada - artigo 82 - precisava de autorização do marido para comparecer em juízo; o desquite - artigo 642 -previa procedimentos especiais; e, os bens de família artigo 647 -ostentavam proteção especial.

O Código admitia os usos e costumes, que deveriam ser provados pelos meios admissíveis em juízo - artigo 259. Os usos e costumes comerciais de praça nacional seriam provados por certidões das repartições incumbidas do respectivo registo e os comerciais estrangeiros por ato autêntico.

Reconhecia o Código da época, como talvez todo o Direito, o pluralismo jurídico.

A oralidade estava presente no Código - não apenas do depoimento pessoal das testemunhas, artigo 245, mas também após a instrução. Nos termos do artigo 269, terminada aquela fase, deveria o juiz fixar os pontos do debate oral. Após, o procurador do autor, do réu e o órgão do Ministério público teriam 20 minutos para expor verbalmente seus motivos. ${ }^{38}$

\footnotetext{
${ }^{37}$ Revogado pelo Decreto-Lei 8.570 de 1946.

${ }^{38}$ A redação do artigo sobre alterações pelo Decreto-Lei n 4.565, de 1942.
} 


\section{Algumas conclusões}

O Código de Processo Civil e Comercial de 1939 está inserido dentro de um projeto de modernização de direito empregado, durante o Estado Novo, pelo Presidente Vargas e coordenado pelo Ministro Francisco Campos.

Vigente até a década de 1970, o Código de Pedro Baptista Martins foi discutido pelos principais intelectuais da época e foi depositário de inúmeras esperanças. Acreditava-se que ele tornaria o processo mais rápido, justo e acessível a todos. Na imprensa foi possível perceber como parte da sociedade postulava um novo Código de Processo; as diversas notícias sobre a elaboração do Código, mesmo em um período de ditadura, mostram uma certa preocupação social com a nova legislação.

Por outro lado, o Código está inserido na mentalidade de que é possível mudar o mundo através de leis e grandes reformas legislativas. A exposição de motivos de Francisco Campos ajuda a entender os princípios básicos que atravessavam toda a legislação do período: superação de um passado considerado, por eles, arcaico para uma caminhada para o progresso, com uma constante intervenção do Estado.

Para Campos o processo era um instrumento político do Estado autoritário, que tinha no Judiciário um dos seus grandes apoiadores. O Estado autoritário e popular, na visão do Ministro, era quem possuía as melhores condições para construção e desenvolvimento do país. Nesse sentido, o Código, como todo o sistema legal, é a marca da força do Estado.

Com uma visão mais técnica, o autor do anteprojeto, Pedro Baptista Martins, parecia ter uma crença - às vezes inocente - no Direito, no Judiciário e no Estado. Ele acreditava no processo como uma forma de humanização social. Para Martins a jurisdição era um dever do Estado, um poder público, que deveria existir para o bem da população. O Código, desta forma, era um instrumento de exercício de direitos.

Se existe diferença entre trabalhar para uma ditadura e trabalhar em uma ditadura, se existe diferença entre um juiz que cumpre a lei e um juiz que faz de tudo para alcançar "um resultado", as experiências do Código de Processo Civil podem ajudar a compreender os 
Revista Eletrônica de Direito Processual - REDP.

Rio de Janeiro. Ano 11. Volume 18. Número 2. Maio a Agosto de 2017

Periódico Quadrimestral da Pós-Graduação Stricto Sensu em Direito Processual da UERJ

Patrono: José Carlos Barbosa Moreira. ISSN 1982-7636. pp. 245-260

www.redp.uerj.br

papéis que os juristas e seus operadores exercem em um Estado de Direito e em uma ditadura.

Mais do que técnica, o Direito e o processo são instrumentos políticos e podem prestar-se a vários fins. E, por mais que os fins não sejam expressos, por mais que o Direito só se preocupe com o descrito nos autos, a história também serve como local de memória, de questionamento e revisão do Direito, mesmo que ele esteja transitado em julgado, prescrito ou oculto.

\section{REFERÊNCIAS BIBLIOGRÁFICAS:}

CÂMARA LEgAL. A.L.. Comentários ao Código de Processo Civil. Rio de Janeiro: Forense, 1942.

CAMPOS, Francisco. Exposição de Motivos. In MARTINS, Pedro Baptista e LEAL, Victor Nunes. Código de Processo Civil. Rio de Janeiro: José Olympio Editora, 1939, p. XXVIII.

DE PLÁCIDO E SILVA. Técnica Forense e Prática Processual. Editora Guaíra Limitada: Curitiba.

FIGUEIREDO, Cândido de. Novo Diccionário da Lingua Portuguesa. Lisboa: Portugal Brasil. Sociedade Editora Arthur Brandão \& Cia. Rua da Condessa, 80, p. 442.

FONSECA, Simões da. Diccionario Encyclopedico. Rio de Janeiro: rua Moreira-cezar,71| Pariz: rue des Saints-Pères,6. H. Garnier, Livreiros - Editores. p. 328.

JORNAL A Noite, Rio de Janeiro.

LIMA, Hildebrando; BARROSO, Gustavo. (org.) Pequeno Dicionário Brasileiro da Língua Portuguesa. Editora Civilização Brasileira S|A: RJ, SP e BA. 8ed, 1949. p. 280.

MARTINS, Pedro Baptista. O Código de Processo Civil e Comercial do Brasil in Revista Forense, Rio de Janeiro, Ano XXXV, número 424, p. 166-167.

MORATO, Francisco. A oralidade in Revista Forense, Rio de Janeiro, Ano XXXV, número 419, p. 11-16. 
Revista Eletrônica de Direito Processual - REDP.

Rio de Janeiro. Ano 11. Volume 18. Número 2. Maio a Agosto de 2017

Periódico Quadrimestral da Pós-Graduação Stricto Sensu em Direito Processual da UERJ

Patrono: José Carlos Barbosa Moreira. ISSN 1982-7636. pp. 245-260

www.redp.uerj.br

RAITANI, Francisco. Prática de Processo Civil, 3a ed., Editora Guaíra Limitada: Curitiba.

SEELAENDER, Airton. Juristas e ditaduras: uma leitura brasileira In FONSECA, Ricardo

Marcelo e SEELAENDER, Airton (Org.). História do Direito em Perspectivas. Curitiba: Juruá, 2009.

SIQUEIRA, Gustavo et ali. The constitutionalists in the Brazilian Estado Novo: notes on the right to strike In Revista da Academia brasileira de Direito Constitucional, v. 8, 2016, Curitiba, pp. 12-32 